\title{
Restraint and eating concern in North European and East Asian women with and without eating disorders in Australia and Singapore
}

\author{
Nerissa Li-Wey Soh, Stephen Touyz, Timothy A. Dobbins, \\ Lois J. Surgenor, Simon Clarke, Michael R. Kohn, Ee Lian Lee, \\ Vincent Leow, Elizabeth Rieger, Ken Eng Khean Ung, Garry Walter
}

\begin{abstract}
Objective: To investigate eating disorder psychopathology, restraint and eating concern in young women with and without an eating disorder from two different ethnic groups in Australia and Singapore.

Method: The relationship of Eating Disorder Examination Questionnaire Global, Restraint and Eating Concern scores to cultural orientation and sociocultural factors was analysed in 154 women with and without an eating disorder. Participants were from the following backgrounds: North European Australian, East Asian Australian, Singaporean Chinese and North European expatriates in Singapore.

Results: Women with eating disorders had similar psychopathology across the cultural groups. Among controls, Singaporean Chinese reported significantly greater overall eating disorder psychopathology than other cultural groups and greater restraint than North European Australians/expatriates. Eating concern was not associated with cultural group overall or acculturation to Western culture. Dissatisfaction with family functioning, socioeconomic status and education level were not significantly associated with any of the eating disorder measures.
\end{abstract}

Nerissa Li-Wey Soh, Research Assistant to the Chair of Child and Adolescent Psychiatry (Correspondence)

Child and Adolescent Mental Health Services, Northern Sydney and Central Coast Area Health Service, New South Wales, Australia; PO Box 142, Coral Tree Family Service, North Ryde, NSW 1670, Australia. Email: nsoh@nsccahs.health.nsw.gov.au

Stephen Touyz, Professor Clinical Psychology, School of Psychology; Co-Director, Peter Beumont Centre for Eating Disorders

School of Psychology, University of Sydney, New South Wales, Australia; Co-Director, Peter Beumont Centre for Eating Disorders, Ashfield, New South Wales, Australia

Timothy A. Dobbins, Lecturer

School of Public Health, University of Sydney, New South Wales, Australia

Lois J. Surgenor, Senior Lecturer

Department of Psychological Medicine, Christchurch School of Medicine and Health Sciences, University of Otago, Christchurch, New Zealand

Simon Clarke, Staff Specialist Paediatrician, Director, Department of Adolescent Medicine; Senior Clinical Lecturer, Faculty of Medicine

Department of Adolescent Medicine, Westmead Hospital, Westmead, New South Wales, Australia; Faculty of Medicine, University of Sydney, New South Wales, Australia

Michael R. Kohn, Senior Staff Specialist, Department of Adolescent Medicine; Senior Clinical Lecturer, Faculty of Medicine
Department of Adolescent Medicine, The Children's Hospital at Westmead, Westmead, New South Wales, Australia; Faculty of Medicine, University of Sydney, New South Wales, Australia

Ee Lian Lee, Senior Consultant Psychiatrist

Department of Behavioural Medicine, Singapore General Hospital, Singapore

Vincent Leow, Consultant Psychiatrist

Private Practice, Bondi Junction, New South Wales, Australia

Elizabeth Rieger, Lecturer

School of Psychology, University of Sydney, New South Wales, Australia Ken Eng Khean Ung, Senior Consultant Psychiatrist and Psychotherapist

Adam Road Hospital, Singapore

Garry Walter, Chair of Child and Adolescent Psychiatry, Discipline of Psychological Medicine; Area Clinical Director, Child and Adolescent Mental Health Services

Discipline of Psychological Medicine, University of Sydney, New South Wales, Australia; Child and Adolescent Mental Health Services, Northern Sydney and Central Coast Area Health Service, New South Wales, Australia

Received 20 November 2006; accepted 20 December 2006. 
Conclusion: In eating disorder psychopathology, the specific symptom of eating concern may transcend cultural influences.

Key words: acculturation, Asian continental ancestry group, cross-cultural comparison, eating disorders, European continental ancestry group.

\section{Australian and New Zealand Journal of Psychiatry 2007; 41:536-545}

Eating disorders (EDs) were once considered Western culture-bound syndromes and the classical patient with anorexia nervosa presented as young, female, well-educated, North European Caucasian, and of high socioeconomic status (SES) [1]. However, reports of EDs in non-Western individuals have been increasing in the international medical literature since the 1970s and the prevalence of EDs in these societies is not always lower than in Western countries [1].

Despite the relatively conforming prevalence and treatment approaches, it has been suggested that non-Western patients with EDs may present differently to their Western counterparts - particularly because of differences in cultural values and social and family environments [1]. For example, fear of fatness, which is a major component of the diagnostic criteria for EDs [2,3], is not a ubiquitous feature of ED pathology [4-6], even among Western cases of EDs [7]. Thus, in some cultural groups, some factors may play a differentially critical or powerful role in eating pathology. Also, very little research has been undertaken into the effects of ethnicity on family dynamics [8] and the few studies into family environment and eating pathology undertaken in non-Western groups have yielded mixed results [9-11]. The highly rigid and cohesive family structure traditionally associated with anorexia nervosa is culturally sanctioned in Asian societies $[9,10]$. This structure may not be pathological if all family members support such a pattern [12] and it may be that dissatisfaction with family functioning rather than the actual level of functioning is associated with ED pathology.

Numerous cross-cultural studies have used ethnicity as a proxy for different cultural groups. This is not ideal because the definition of a particular culture spans a wide range of characteristics beyond ethnicity, and members of a particular ethnic group are not necessarily homogenous in their cultural identity, language, SES or immigration status $[13,14]$. This heterogeneity of cultural beliefs within an ethnic group also makes it difficult to justify the pooling of ethnic groups that characterizes various studies [15]. Moreover, comparatively few studies have investigated a particular ethnic group in both a Western country and country of origin using the same methodology [16] and very few use formal measures of acculturation to Western culture or retention of traditional culture in their analyses of ED pathology [11]. Also, there are suggestions that SES may be a more important risk factor than ethnicity and culture, because non-Western groups were historically members of less affluent sectors of society [1]. In addition, no study has yet examined ED pathology in North European individuals now living in a non-Western society, who may potentially have greater pathology in view of their exposure to the society's smaller body norm. Arising from these specific gaps in the literature, this study examines ED psychopathology, restraint and eating concern in North European and East Asian women with and without EDs in Australia and Singapore in terms of their acculturation profile and sociocultural risk factors of family functioning, SES and education level. We hypothesize that (i) irrespective of cultural group, higher levels of ED psychopathology, restraint and eating concern will be associated with greater orientation to Western culture; (ii) lower levels of ED psychopathology, restraint and eating concern will be associated with greater orientation to traditional cultures; (iii) Asian women in Asia will have less severe ED psychopathology, restraint and eating concern than women in a Western country; and (iv) North European expatriate women in an Asian country will have higher levels of ED psychopathology, restraint and eating concern than North European women still living in a Western country. Secondary hypotheses are that higher levels of ED psychopathology, restraint and eating concern will be associated with greater dissatisfaction with family functioning, higher SES and higher education level. 


\section{Methods}

\section{Participants}

Participants were women aged $14-38$ years who were recruited as part of a larger cross-cultural ED research programme. The women were either undergoing treatment for an ED as classified by DSM-IV criteria by clinical diagnosis [2] (anorexia nervosa, bulimia nervosa and eating disorder not otherwise specified) or had never been diagnosed with an ED. Participants in Australia were either born in Australia or migrated to Australia by the age of 12 years. East Asian subjects included participants of Chinese, Vietnamese and Korean descent. ED participants were recruited from four teaching hospitals in Sydney and two teaching hospitals in Singapore through direct invitation to groups of patients by researchers and ward staff. Control participants were recruited from a variety of sites: Australian participants through University of Sydney by advertising and word of mouth, Singaporean Chinese participants through the nursing department of one of the teaching hospitals in Singapore by the department director's direct invitation, and North European expatriate participants through an international school in Singapore through direct invitation to groups of students and staff. There was no expatriate group with EDs assessed.

Exclusion criteria were non-fluency in spoken or written English; pregnancy or lactating; age not in the aforementioned age range; self-identification with a cultural group other than North European or East Asian. In addition, patients with binge eating disorder were excluded among participants with EDs because binge eating disorder is currently a research diagnosis and the study's focus was on the three more traditional and established ED subtypes [2]. The study was approved by the following ethics committees: in Australia, the Human Research Ethics Committee of University of Sydney, the Ethics Review Committee of the Central Sydney Area Health Service and the Human Research Ethics Committee of the Western Sydney Area Health Service; and in Singapore, the Ethics Committee of Singapore General Hospital. Written informed consent was obtained from all participants. Participants in Australia who were under 16 and those in Singapore who were under 21 were deemed minors and consent was obtained from their parents.

\section{Questionnaires}

\section{Demographics questionnaire}

Participants were first invited to complete a questionnaire recording ethnicity/cultural group, level of education and parents' occupations. SES was determined using a prestige scale of 1-7 for paternal occupation, where 1 represents the highest SES and 7 the lowest [17]. In the event that the participant's father was not residing with the participant, maternal occupation was used instead. Because many participants were young and still studying, they were not necessarily independent economically and education level was included along with parental occupation to provide a more complete picture of their social status. Participants then completed the following psychometric measures.

\section{Eating Disorder Examination Questionnaire, version 4}

The Eating Disorder Examination Questionnaire, version 4 (EDE-Q) [18] assesses an individual's ED psychopathology over the past 4 weeks and is based on the Eating Disorder Examination [19], an investigator-based interview measure. The Global score, Restraint and Eating Concern scores were used.

\section{Vancouver Index of Acculturation}

The Vancouver Index of Acculturation (VIA) [20] was used as a measure of cultural orientation and has two scales: the Mainstream or Western scale (orientation to Australian/Western culture) and the Heritage or Traditional scale (orientation to traditional culture). The terminology of the VIA was adjusted following consultation with the VIA's author. For Australian participants, the term 'heritage' was changed to 'cultural minority' and the term 'North American' was changed to 'Australian'; for participants in Singapore, the term 'heritage' was changed to 'Chinese' and the term 'North American' to 'Western' [Ryder A: personal communication]. Participants were instructed to answer the VIA's items on cultural minority with respect to their own cultural background; participants of North European descent were instructed to interpret these items with respect to cultural minority groups in general.

\section{Family Adaptability and Cohesion Evaluation Scale II}

The Family Adaptability and Cohesion Evaluation Scale II (FACES II) [21] assesses the level of perceived family connectedness or separateness (cohesion) and the level of rigidity or flexibility (adaptability). Participants completed the FACES II twice, recording their perceived and ideal family functioning. Dissatisfaction levels with Cohesion and Adaptability were defined as the magnitude of difference between Perceived and Ideal FACES II subscale scores.

Height and weight were then taken in duplicate using the International Society for the Advancement of Kinanthropometry technique [22] with the participant lightly clad: stretched height was recorded using a graph paper wall chart and headboard to the nearest millimetre, and weight was recorded using digital scales (Tanita 1618, Tanita Corporation, Tokyo, Japan) to the nearest $200 \mathrm{~g}$. Where duplicates were $>2 \%$ apart, a third measurement was taken. Median values were used to calculate body mass indices $\left(\mathrm{BMI}=\mathrm{kg} \mathrm{m}^{-2}\right)$.

\section{Statistical analyses}

Analyses were conducted with SPSS for Windows version 11.5.0 (SPSS Inc., Chicago, IL, USA) software. Age, SES and BMI were analysed using one-way analyses of variance with post-hoc Scheffe tests. To assess the relationship between ED pathology and sociocultural factors, multiple linear regression of the dependent variables EDE-Q Global, Restraint and Eating Concern scores was undertaken against clinical (ED/control) status, cultural group, VIA Australian/Western score, VIA Traditional score, FACES II magnitude of Perceived-Ideal Family Cohesion, FACES II 
magnitude of Perceived-Ideal Family Adaptability, education level, SES and age. Interactions between cultural group and clinical status, cultural group and FACES II magnitude of Perceived-Ideal Family Cohesion, and cultural group and FACES II magnitude of Perceived-Ideal Family Adaptability were tested in the baseline models. The process of backwards elimination was used.

To assess acculturation profiles, repeated-measures analyses of variance followed by pairwise comparisons with Bonferroni adjustments to the significance level for multiple comparisons (significance level of $\mathrm{p}<0.05$ ) were applied to compare VIA Australian/Western and Traditional culture subscale scores within each cultural and diagnostic group and to compare the scores of each VIA subscale across the groups. The same method was applied to Perceived and Ideal Cohesion scores and then to Perceived and Ideal Adaptability scores to assess family functioning profiles.

\section{Results}

\section{Descriptive statistics}

Table 1 shows the participants' mean age, SES, BMI and the highest level of education level attained. There was a significant difference across the groups for age $\left(\mathrm{F}_{6,147}=3.27, \mathrm{p}=0.005\right)$, SES $\left(\mathrm{F}_{6,141}=10.62, \mathrm{p}<0.001\right)$ and BMI $\left(\mathrm{F}_{6,146}=10.35, \mathrm{p}<0.001\right)$. For age, post-hoc tests indicated a difference between control Singaporean Chinese and control expatriates $(p=0.04)$ while all other groups were similar to each other $(p>0.06)$. For SES, control Singaporean Chinese reported lower SES than control North European Australians and expatriates $(\mathrm{p}<0.001)$ and ED North European Australians $(\mathrm{p}=0.002)$. Control East Asian Australian subjects reported lower SES than both control North European Australian subjects $(p=0.002)$ and expatriates $(p=0.02)$, but there were no other differences in SES ( $p>0.09)$. ED North European Australian subjects had lower mean BMIs than control North European Australian subjects ( $p=0.002)$, East Asian Australian $(p=0.001)$ and Singaporean Chinese $(p<0.001)$ and ED Singaporean Chinese subjects also had lower BMIs than control North European Australian $(\mathrm{p}=0.05)$, East Asian Australian $(\mathrm{p}=0.02)$ and Singaporean Chinese subjects $(\mathrm{p}=0.001)$. There were no other differences in BMI across the groups $(\mathrm{p}>0.2)$.

Education level was not compared statistically due to the large number of cells with few responses. However, from a descriptive view, two-thirds of participants reported having year 10 to bachelor degree education, which reflects the study sample's age profile.

Table 2 shows mean scores for Global, Eating Concern and Restraint scores, VIA Western/Australian and Traditional scores and FACES II Perceived and Ideal scores. Their analyses are presented in turn here.

\section{Multiple linear regression of EDE-Q scales}

Table 3 shows the partial regression coefficients and their $95 \%$ confidence intervals, test statistics and significance of predictors in the final regression models for EDE-Q Global, Restraint and Eating Concern scores. The interactions between cultural group and FACES II magnitude of Perceived-Ideal Cohesion, and cultural group and magnitude of Perceived-Ideal Adaptability, were not significant for any of the three dependent variables. Magnitude of Perceived-Ideal Cohesion and Adaptability, VIA Traditional subscale scores, education level and SES as main effect variables were not significant and were not confounders of each other or of the variables retained in each of the three final models. Because there was no difference between North European expatriates and North European Australians, the two groups were combined. Age was retained throughout for face validity.

\section{Global score}

Higher VIA Western scores were associated with higher EDE-Q Global scores after controlling for age, clinical status and cultural group. The interaction between cultural group and clinical status remained significant. There was no difference in ED women's EDE-Q Global scores by cultural group $\left(\mathrm{F}_{2,146}=0.37, \mathrm{p}=0.7\right)$, but within each cultural group ED women scored significantly higher than control women: in North European Australian $\left(\mathrm{t}_{146}=8.49\right.$, $\mathrm{p}<0.001)$; in East Asian Australian $\left(\mathrm{t}_{146}=2.53, \mathrm{p}=0.01\right)$; and in Singaporean Chinese subjects $\left(\mathrm{t}_{146}=2.34, \mathrm{p}=0.02\right)$. However, in control women, Singaporean Chinese scored significantly higher than North European Australians/expatriate subjects $\left(t_{146}=3.53\right.$, $\mathrm{p}=0.001)$ and marginally higher than control East Asian Australian subjects $\left(\mathrm{t}_{146}=-1.89, \mathrm{p}=0.06\right)$. There was no difference between control East Asian Australian and North European Australian/expatriate subjects $\left(\mathrm{t}_{146}=1.83, \mathrm{p}=0.07\right)$.

\section{Restraint}

High VIA Australian/Western scores were significantly associated with higher Restraint scores. The interaction between cultural group and clinical status remained significant. There was no difference in mean adjusted Restraint scores across the cultural groups for women with $\operatorname{EDs}\left(\mathrm{F}_{2,146}=0.22, \mathrm{p}=0.08\right)$. Control North European Australian/expatriate and East Asian Australian subjects were similar $\left(t_{146}=1.66, p=0.1\right)$ but while control Singaporean Chinese were similar to control East Asian Australian subjects $\left(t_{146}=1.68, p=0.1\right)$, the former had significantly greater Restraint than North European Australian/expatriate subjects $\left(\mathrm{t}_{146}=3.16, \mathrm{p}=0.002\right)$. ED women had significantly higher Restraint scores than controls in all three groups: North European/ expatriate $\left(\mathrm{t}_{146}=7.33, \mathrm{p}<0.001\right)$, East Asian Australian $\left(\mathrm{t}_{146}=\right.$ $2.27, \mathrm{p}=0.03)$ and Singaporean Chinese subjects $\left(\mathrm{t}_{146}=2.21, \mathrm{p}=\right.$ $0.03)$.

\section{Eating Concern}

The interaction between clinical status and cultural group was not significant $\left(\mathrm{F}_{2,129}=2.70, \mathrm{p}=0.07\right)$. Although VIA Australian/ Western score was not a significant predictor of Eating Concern, it was retained as a variable of interest and for consistency with the other analyses. Cultural group overall was also not significant. Only clinical status was significant, where ED women had 


\begin{tabular}{|c|c|c|c|c|c|c|c|c|}
\hline & $\begin{array}{c}\text { Control } \\
\text { NEA }\end{array}$ & ED NEA & $\begin{array}{c}\text { Control } \\
\text { EAA }\end{array}$ & ED EAA ${ }^{\dagger}$ & $\begin{array}{l}\text { Control NE } \\
\text { expatriate }\end{array}$ & Control SC & ED SC & Total \\
\hline $\mathrm{n}$ & 32 & 35 & 22 & 2 & 12 & 33 & 18 & 154 \\
\hline Age (years) & 21.5 & 21.1 & 21.3 & 16.0 & 17.3 & 22.2 & 22.5 & 21.3 \\
\hline$(95 \% \mathrm{Cl})$ & $(20.4-22.5)$ & $(19.6-22.6)$ & $(19.8-22.9)$ & & $(13.5-21.2)$ & $(21.1-23.3)$ & $(19.9-25.0)$ & $(20.6-21.9)$ \\
\hline $\begin{array}{l}\text { SES }(/ 7) \\
(95 \% \mathrm{Cl})\end{array}$ & $\begin{array}{l}3.00 \\
(2.66-3.33)\end{array}$ & $\begin{array}{l}3.52^{\ddagger} \\
(3.03-4.00)\end{array}$ & $\begin{array}{l}4.46^{\S} \\
(3.75-5.17)\end{array}$ & 4.15 & $\begin{array}{l}2.85 \\
(2.31-3.39)\end{array}$ & $\begin{array}{l}4.83^{\circ} \\
(4.58-5.07)\end{array}$ & $\begin{array}{l}4.08 \\
(3.63-4.52)\end{array}$ & $\begin{array}{l}3.82^{\#} \\
(3.61-4.03)\end{array}$ \\
\hline $\mathrm{BMI}\left(\mathrm{kg} \mathrm{m}^{-2}\right)$ & 21.41 & $17.43^{\ddagger}$ & 22.09 & 14.58 & 20.61 & 22.58 & 17.72 & $20.29^{*}$ \\
\hline$(95 \% \mathrm{Cl})$ & $(20.51-22.31)$ & $(16.49-18.37)$ & $(20.71-23.46)$ & & $(18.83-22.38)$ & $(20.96-24.20)$ & $(15.42-20.02)$ & $(19.64-20.94)$ \\
\hline \multicolumn{9}{|c|}{ Highest level of education attained, $\mathrm{n}(\%)$} \\
\hline Less than year 10 & $0(0)$ & $0(0)$ & 2 (9) & $1(50)$ & $10(83)$ & $6(18)$ & $0(0)$ & $19(12.4)$ \\
\hline Years $10-12$ inclusive & $9(28)$ & $20(57)$ & $1(5)$ & $1(50)$ & $0(0)$ & $1(3)$ & $10(59)$ & $42(27.5)$ \\
\hline Undergraduate & $16(50)$ & $4(11)$ & $11(50)$ & $0(0)$ & $0(0)$ & $1(3)$ & $1(6)$ & $33(21.6)$ \\
\hline Bachelor degree & $6(19)$ & $7(20)$ & $6(27)$ & $0(0)$ & $0(0)$ & 3 (9) & $6(35)$ & $28(18.3)$ \\
\hline Postgraduate & $1(3)$ & $1(3)$ & $2(9)$ & $0(0)$ & $2(17)$ & $0(0)$ & $0(0)$ & $6(3.9)$ \\
\hline Apprenticeship/Technical college & $0(0)$ & $3(9)$ & $0(0)$ & $0(0)$ & $0(0)$ & $22(67)$ & $0(0)$ & $25(16.3)$ \\
\hline Total & $32(100)$ & $35(100)$ & $22(100)$ & $2(100)$ & $12(100)$ & $33(100)$ & $17(100)$ & $153(100)$ \\
\hline
\end{tabular}




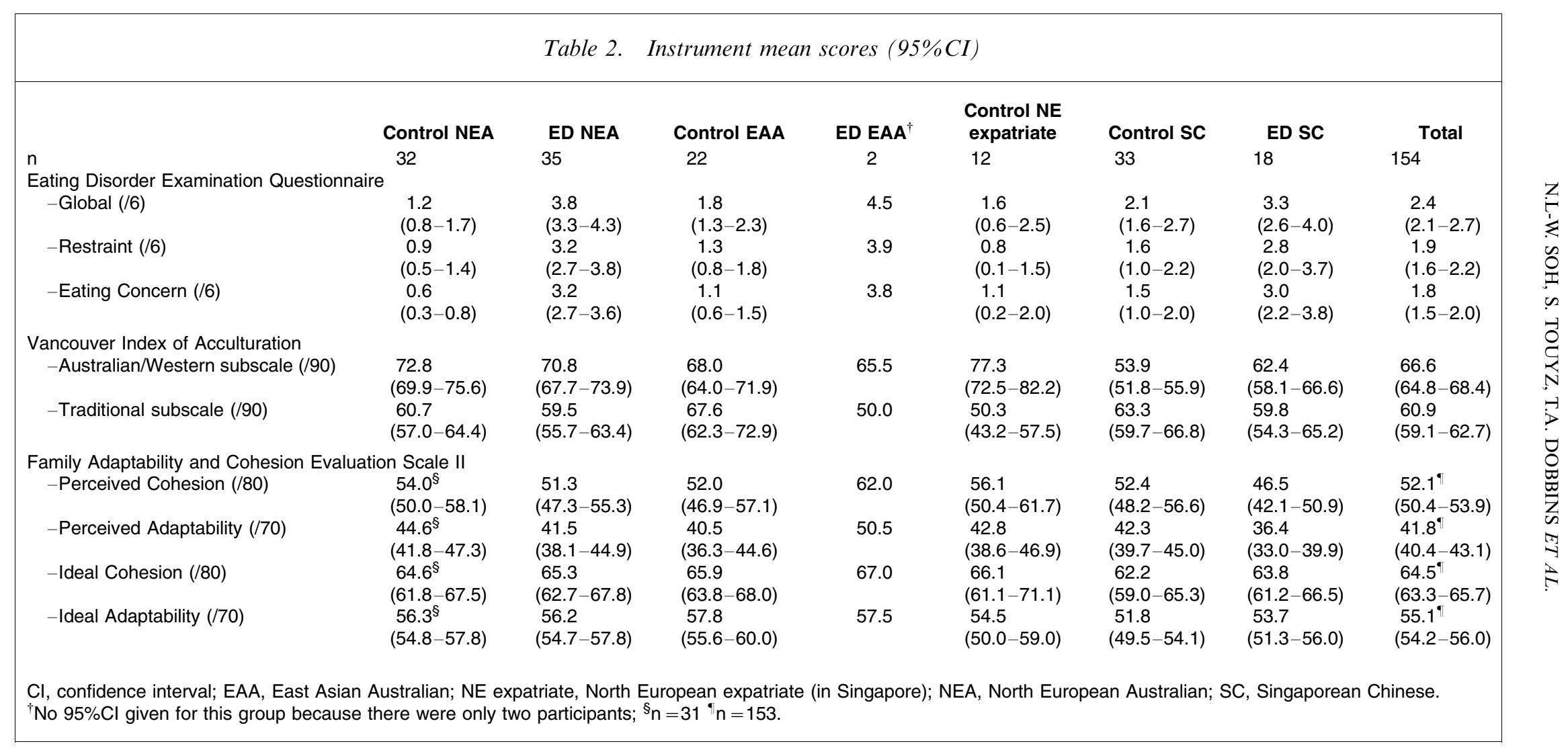


Table 3. Multiple linear regression models

Global score $(/ 6)\left(R^{2}=0.39\right)$

VIA Australian/Western culture (/90)

Age (years)

Clinical status

Cultural group

Interaction cultural group $\times$ clinical status

Restraint (/6) $\left(R^{2}=0.33\right)$

VIA Australian/Western culture (/90)

Age (years)

Caseness

Cultural group

Interaction cultural group $\times$ clinical status

Eating Concern $(/ 6)\left(R^{2}=0.42\right)$

VIA Australian/Western score (/90) $\quad 0.01$

Age (years)

Clinical status

Cultural group
Partial regression coefficient

0.03

$-0.04$

2.61

0.03

$-0.03$

2.47

$-0.03$

2.13
$95 \% \mathrm{Cl}$

$0.00,0.06$

$-0.09,0.01$

$2.00,3.21$

$0.01,0.06$

$-0.09,0.03$

$1.80,3.13$

$-0.01,0.03$

$-0.08,0.02$

$1.71,2.55$
Test statistic

$t_{146}=2.24$

$\mathrm{t}_{146}=-1.45$

$\mathrm{t}_{146}=8.49$

$\mathrm{F}_{2,146}=6.29$

$\mathrm{F}_{2,146}=5.19$

$\mathrm{t}_{146}=2.41$

$t_{146}=-1.07$

$\mathrm{t}_{146}=7.33$

$\mathrm{F}_{2,146}=5.05$

$F_{2,146}=3.50$

$\mathrm{t}_{148}=0.85$

$\mathrm{t}_{148}=-1.32$

$t_{148}=10.01$

$F_{2,148}=2.36$ p

0.03

0.1

$<0.001$

0.002

0.007

0.02

0.3

$<0.001$

0.008

0.03

0.4

0.2

$<0.001$

0.1

$\mathrm{Cl}$, confidence interval; VIA, Vancouver Index of Acculturation.

significantly greater Eating Concern scores than control women $\left(\mathrm{t}_{148}=10.01, \mathrm{p}<0.001\right)$.

\section{Acculturation to Western culture and retention of traditional cultures}

There was a significant difference between the total sample's VIA Australian/Western and VIA Traditional scores $\left(\mathrm{F}_{1,147}=28.10\right.$, $\mathrm{p}<0.001)$ and across the seven cultural and diagnostic groups $\left(\mathrm{F}_{6,147}=5.51, \mathrm{p}<0.001\right)$. The interaction between the differences in VIA subscale scores and the cultural and diagnostic groups was also significant $\left(\mathrm{F}_{6,147}=16.80, \mathrm{p}<0.001\right)$. In control North European Australian, ED North European Australian and control North European expatriate subjects, VIA Australian/Western scores were significantly higher than Traditional scores $(\mathrm{p}<$ 0.001). In contrast, control Singaporean Chinese subjects had significantly higher Traditional scores than Australian/Western scores $(\mathrm{p}<0.001)$. There was no significant difference between the Australian/Western and Traditional scores for control East Asian Australian $(p=0.9)$, ED East Asian Australian $(p=0.09)$ or ED Singaporean Chinese subjects $(\mathrm{p}=0.4)$.

On examining the VIA scores across the cultural and diagnostic groups, control Singaporean Chinese had significantly lower VIA Australian/Western scores than ED Singaporean Chinese $(p=0.02)$ and control North European Australian, East Asian Australian and North European expatriate subjects $(\mathrm{p}<0.001)$. ED Singaporean Chinese also had significantly lower VIA Australian/Western scores than control North European Australian $(p=0.001)$, ED North European Australian $(\mathrm{p}=0.02)$ and control North European expatriate subjects $(p<0.001)$, but were similar to control $(p=0.9)$ and ED East Asian Australian subjects $(\mathrm{p}=1)$. North European expatriates did not differ from any of the groups in Australia (control North European Australian, $\mathrm{p}=1$; ED North European
Australian, $\mathrm{p}=0.4$; or ED East Asian Australian, $\mathrm{p}=1$ ) except when compared to control East Asian Australian subjects, who scored marginally lower $(p=0.051)$. There were no differences in VIA Australian/Western scores across the groups in Australia ( $\mathrm{p}>$ 0.8 ) and ED East Asian Australian subjects did not differ from any of the other cultural and diagnostic groups $(p=1)$. For Traditional scores, North European expatriates scored significantly lower than control East Asian Australian $(\mathrm{p}<0.001)$ and control Singaporean Chinese subjects $(\mathrm{p}=0.01)$, but all other comparisons between groups were not significant $(\mathrm{p}>0.2)$.

\section{Perceived and ideal family cohesion and adaptability}

There was a significant difference between Perceived and Ideal Cohesion scores overall $\left(\mathrm{F}_{1,146}=80.84, \mathrm{p}<0.001\right)$, but no significant difference across the groups for Perceived and Ideal Cohesion $\left(\mathrm{F}_{6,146}=1.14, \mathrm{p}=0.3\right)$ and no significant interaction between Perceived-Ideal Cohesion and cultural and diagnostic group $\left(\mathrm{F}_{6,146}=1.75, \mathrm{p}=0.1\right)$. Control expatriates preferred a more cohesive family than they currently perceived they had $(\mathrm{p}=$ 0.001), as did control North European Australian, East Asian Australian and Singaporean Chinese and ED North European Australian and Singaporean Chinese women $(p<0.001)$, but ED East Asian Australian women reported similar Perceived and Ideal Cohesion $(\mathrm{p}=0.5)$.

In regard to Adaptability, there was a significant difference between Perceived and Ideal scores overall $\left(\mathrm{F}_{1,146}=141.95, \mathrm{p}<\right.$ $0.001)$, a difference across the groups for Perceived and Ideal Adaptability $\left(\mathrm{F}_{6,146}=2.51, \mathrm{p}=0.02\right)$ and a significant interaction between Perceived-Ideal Adaptability and cultural and diagnostic group $\left(\mathrm{F}_{6,146}=3.17, \mathrm{p}=0.006\right)$. ED East Asian Australians reported similar Perceived and Ideal adaptability $(p=0.2)$ but the other six groups all preferred a more flexible family than they perceived they currently had $(\mathrm{p}<0.001)$. ED Singaporean Chinese 
perceived their families as more rigid than control North European Australian subjects $(p=0.03)$ and control Singaporean Chinese preferred a more rigid family than control North European Australian $(p=0.02)$, control East Asian Australian $(p=0.002)$ and ED North European Australian subjects $(p=0.02)$. There were no other significant differences in Perceived or Ideal Adaptability between groups $(\mathrm{p}>0.3)$.

\section{Discussion}

In general, greater acculturation to Western culture was significantly associated with greater overall ED psychopathology and restraint, concurring with our hypotheses. However, after adjusting for acculturation, women with EDs of Singaporean Chinese, North European Australian, and East Asian Australian backgrounds had similar overall ED psychopathology, restraint, and eating concern. It was in control women where differences in ED psychopathology emerged. Control women in both Australian groups and the expatriate group were similar but Singaporean Chinese controls had significantly greater or marginally greater overall ED psychopathology than the other control groups and significantly greater restraint than the North European Australian/expatriate controls. The finding of similar overall ED psychopathology and restraint between Singaporean Chinese women with EDs and their counterparts from other cultural groups is consistent with the limited number of other studies in Singaporean Chinese patients $[23,24]$. The findings also concur with observations of greater pathology in less Westernized groups, such as in Iranian women [25], Japanese women [26], and Korean women [27], and serve to highlight that women living in a non-Western society do not necessarily have a lower level of ED pathology.

In a previous study, the lack of difference in body shape dissatisfaction and weight and shape concern observed between control and ED Singaporean Chinese subjects despite controlling for orientation to Western culture [28] suggested that other factors may play a greater role in Singaporean women's ED pathology. Unlike body image measures, the EDE-Q Global, Restraint and Eating Concern scales utilized in the present study were able to distinguish between ED and control status in all the cultural groups, including the Singaporean Chinese subjects. Thus, in Singaporean Chinese women, restraint and eating concern may play a greater role in the expression of ED psychopathology compared to weight and shape concerns. Also, only
ED status significantly predicted Eating Concern scores, suggesting that eating concern may be a universal distinguishing feature of a clinical ED across the cultural groups investigated, including in Singaporean Chinese women.

The significant association between acculturation to Western culture and ED pathology concurs with other studies [29-32], although many of these studies did not examine the same ethnic group in two different cultural settings. Abdollahi and Mann observed that in Iranian women living in Iran, the level of acculturation was positively and significantly associated with Restraint scores, which mirrored the present study's findings, but was not significantly associated with the EDE-Q subscales for Weight and Shape Concern [25]. In contrast, orientation to traditional cultures had no significant association with overall ED psychopathology, eating concern or restraint, thus failing to support our hypothesis that adherence to traditional values would be protective against ED symptomatology. The present findings do, however, concur with Iyer and Haslam's observations in South Asian women [33].

It has been suggested that the once protective effect of traditional cultures has eroded [34] and some studies have found orientation to traditional culture to be associated with increased ED pathology $[1,35,36]$. Bhugra and Bhui suggested that alienation from one's society may promote eating and body image disturbances in an individual [37]. However, in the present study, women with EDs did not score lower on either the traditional or Western scales than their control counterparts. Indeed, within each cultural group, ED and control women were mostly similar in their orientation to either Western or traditional culture, the only significant difference being in the Singaporean Chinese women. For these women it was controls who had a significantly lower orientation to Western culture when compared to their ED counterparts as well as to all other groups. In contrast, control and ED East Asian Australian and ED Singaporean Chinese women had similar Western and Traditional scores, which suggests that they are 'bilocal' [38] and therefore similarly affiliated to both cultures. Overall, the acculturation profiles suggest that the women with EDs were not alienated when compared to their control counterparts.

It was hypothesized that North European expatriate individuals would exhibit greater eating disturbances than their counterparts who remained in a Western country, in view of the smaller Asian body norm they would be exposed to in Singapore. However, the expatriate women in the present study did not differ 
from North European Australian women in overall ED psychopathology, eating concern or restraint after adjusting for significant covariates, and thus the hypothesis was not supported. From their acculturation profile, North European expatriate women in Singapore appear to inhabit a sociocultural enclave similar to the sociocultural environment of Australian women: they were similar to both control and ED North European Australian subjects in their affiliation to Western culture. The expatriate group's affiliation to traditional non-Western cultures was also similar to that of both control and ED North European Australian women and, like the North European Australian women, they reported greater affiliation with Western culture than with traditional cultures. That the expatriates had significantly lower affiliations to traditional cultures than control East Asian Australian and control Singaporean Chinese women, despite living in an Asian society, may reflect their being slightly younger, the sociocultural niche they inhabit and possibly a conscious attachment to their Western identities.

With regard to our secondary hypotheses, there was a consistent absence of association between ED psychopathology and the sociocultural factors SES, education level and dissatisfaction with family cohesion and adaptability. Also, no distinct pattern in perceived or ideal family functioning according to the Circumplex Model of Marital and Family Systems [12] emerged with regard to clinical status. These sociocultural factors were analysed because the literature suggested that they may override ethnicity or culture as risk factors for EDs [1,12]. Although the present study's results did not concur with our hypotheses, it highlights the permeation of ED symptomatology across the social classes [39] and the inconsistent empirical evidence for a specific constellation of family dynamics associated with EDs [1].

Strengths of the present study include the narrow definition of 'East Asian' used in recruitment and deliberately maintaining East Asian Australian and Singaporean Chinese participants as separate groups throughout the analyses, because differences within an ethnic group residing in two different cultural environments was a major focus of this research. This is also the first study to investigate North European Caucasian women living in an Asian country. Future research should include a larger study sample, particularly of East Asian Australian subjects, to allow for analysis by ED subtype. The validity of eating concern as a transcultural factor in ED psychopathology also needs to be confirmed with a larger study sample and across diverse ethnic groups.

\section{Conclusions}

Singaporean Chinese women with EDs exhibited similar overall ED psychopathology, eating concern, and restraint when compared to their North European Australian and East Asian Australian counterparts. However, among community samples without an ED, Singaporean Chinese women had significantly greater eating disturbances when compared to either group of Australian women, despite adjusting for acculturation to Western culture. Also, eating concern emerged as a potential distinguishing criterion for clinical ED status, which may transcend cultural groups.

\section{Acknowledgements}

We thank the staff of Royal Prince Alfred Hospital, Wesley Private Hospital, Rozelle Hospital, Westmead Hospital, Singapore General Hospital, National University Hospital Singapore and the Australian International School Singapore for their support and assistance, and all of the participants for taking part. The late Pierre Beumont, Professor of Psychological Medicine at University of Sydney, was an active contributor to the present study prior to his untimely death in October 2003. This study was partly supported by the Edith Mary Rose Travelling Scholarship. Part of this manuscript was presented at the Australian and New Zealand Academy for Eating Disorders 3rd Annual Conference (2005) and the Eating Disorders Research Society Meeting (2006), and was submitted as part of a doctoral thesis to University of Sydney.

\section{References}

1. Soh NL, Touyz SW, Surgenor LJ. Eating and body image disturbances across cultures: a review. Eur Eat Disord Rev 2006; $14: 54-65$.

2. American Psychiatric Association. Diagnostic and statistical manual of mental disorders. Washington DC: American Psychiatric Association, 1994.

3. World Health Organization. ICD-10. Classification of mental and behavioural disorders. Clinical descriptions and diagnostic guidelines. Geneva: World Health Organization, 1992.

4. Khandelwal SK, Saxena S. Anorexia nervosa in people of Asian extraction. Br J Psychiatry 1990; 157:783-784.

5. Al-Alami MS, Beumont PJV, Touyz SW. The further development of the concept of anorexia nervosa. In: Beumont PJV, Burrows GD, Casper RC, eds. Handbook of eating disorders part 1: anorexia and bulimia nervosa, Amsterdam: Elsevier, 1987:117-141. 
6. Lee S, Ho TP, Hsu LKG. Fat phobic and non-fat phobic anorexia nervosa: a comparative study of 70 Chinese patients in Hong Kong. Psychol Med 1993; 23:999-1017.

7. Palmer RL. Weight concern should not be a necessary criterion for the eating disorders: a polemic. Int J Eat Disord 1993; 14:459-465.

8. Steinberg AB, Phares V. Family functioning, body image, and eating disturbances. In: Thompson JK, Smolak L, eds. Body image, eating disorders, and obesity in youth: assessment, prevention, and treatment, Washington DC: American Psychological Association, 2001:127-147.

9. Kok LP, Tian CS. Susceptibility of Singapore Chinese schoolgirls to anorexia nervosa: part II (family factors). Singapore Med J 1994; 35:609-612.

10. Bhugra D, Bhui K, Gupta KR. Bulimic disorders and sociocentric values in north India. Soc Psychiatry Psychiatr Epidemiol 2000; 35:86-93.

11. Tsai G, Curbow B, Heinberg L. Sociocultural and developmental influences on body dissatisfaction and disordered eating attitudes and behaviors of Asian women. J Nerv Ment Dis 2003; 191:309-318.

12. Olson DH. Circumplex model of marital and family systems. $J$ Fam Ther 2000; 22:144-167.

13. The McKnight Investigators. Risk factors for the onset of eating disorders in adolescent girls: results of the McKnight Longitudinal Risk Factor Study. Am J Psychiatry 2003; 160:248-254

14. Kennedy AA, Templeton L, Gandhi A, Gorzalka BB. Asian body image satisfaction: ethnic and gender differences across Chinese, Indo-Asian, and European-descent students. Eat Disord J Treat Prev 2004; 12:321-336.

15. Wildes JE, Emergy RE, Simons AD. The roles of ethnicity and culture in the development of eating disturbance and body dissatisfaction: a meta-analytic review. Clin Psychol Rev 2001; 24:521-551.

16. Mumford DB, Choudry IY. Body dissatisfaction and eating attitudes in slimming and fitness gyms in London and Lahore: a cross-cultural study. Eur Eat Disord Rev 2000; 8:217-224.

17. Daniel A. Prestige of occupations and a scale of occupational prestige. In: Daniel A, ed. Power, privilege and prestige: occupations in Australia, Melbourne: Longman Cheshire, 1983:193-206.

18. Fairburn CG, Beglin SJ. Assessment of eating disorders: interview or self-report questionnaire. Int J Eat Disord 1994; 46:363-370.

19. Fairburn CG, Cooper Z. The Eating Disorder Examination (12 edn). In: Fairburn CG, Wilson GT, eds. Binge eating. nature, assessment and treatment, New York: Guilford Press, 1993:317-360.

20. Ryder AG, Alden LE, Paulhus DL. Is acculturation unidimensional or bidimensional? A head-to-head comparison in the prediction of personality, self-identity, and adjustment. J Pers Soc Psychol 2000; 79:49-65.

21. Olson DH, Bell R, Portner J. FACES II. In: Olson DH, ed. Family inventories manual, Minneapolis, MN: Life Innovations, 1992:1-20
22. International Society for the Advancement of Kinanthropometry. International standards for anthropometric assessment. Potchefstroom, RSA: North-West University, 2001.

23. Lee HY, Lee EL, Pathy P, Chan YH. Anorexia nervosa in Singapore: an eight-year retrospective study. Singapore Med J 2005; 46:275-281.

24. Ung EK, Lee S, Kua EH. Anorexia nervosa and bulimia: a Singapore perspective. Singapore Med J 1997; 38:332-335.

25. Abdollahi P, Mann T. Eating disorder symptoms and body image concerns in Iran: comparisons between Iranian women in Iran and in America. Int J Eat Disord 2001; 30:259-268.

26. Kusano-Schwarz M, von Wietersheim J. EDI results of Japanese and German women and possible sociocultural explanations. Eur Eat Disord Rev 2005; 13:411-416.

27. Jackson SC, Keel PK, Lee YH. Trans-cultural comparison of disordered eating in Korean women. Int J Eat Disord 2006; 39:498-502.

28. Soh NL, Touyz SW, Dobbins T et al. Eating disturbances and acculturation in women with and without eating disorders in Sydney and Singapore. In: 3rd Annual Australian and New Zealand Academy for Eating Disorders Conference. Sydney, 2005:19-20.

29. Gunewardene A, Huon GF, Zheng R. Exposure to Westernization and dieting: a cross-cultural study. Int $J$ Eat Disord 2001; 29:289-293.

30. Ball K, Kenardy J. Body weight, body image, and eating behaviours: relationships with ethnicity and acculturation in a community sample of young Australian women. Eat Behav 2002; 3:205-216.

31. Al-Subaie AS. Some correlates of dieting behavior in Saudi schoolgirls. Int J Eat Disord 2000; 28:242-246.

32. Mumford DB, Whitehouse AM, Choudry IY. Survey of eating disorders in English-medium schools in Lahore, Pakistan. Int J Eat Disord 1992; 11:173-184.

33. Iyer DS, Haslam N. Body image and eating disturbance among South Asian-American women: the role of racial teasing. Int $J$ Eat Disord 2003; 34:142-147.

34. Miller MN, Pumariega AJ. Culture and eating disorders: a historical and cross-cultural review. Psychiatry 2001; 64: 93-110.

35. Jennings PS, Forbes D, McDermott B, Juniper S, Hulse G. Acculturation and eating disorders in Asian and Caucasian Australian adolescent girls. Psychiatry Clin Neurosci 2005; 59:56-61.

36. Mumford DB, Whitehouse AM, Platts M. Sociocultural correlates of eating disorders among Asian schoolgirls in Bradford. Br J Psychiatry 1991; 158:222-228.

37. Bhugra D, Bhui K. Eating disorders in teenagers in East London: a survey. Eur Eat Disord Rev 2003; 11:46-57.

38. Marks LI. Deconstructing locus of control: implications for practitioners. J Counsel Dev 1998; 76:251-260.

39. Fear JL, Bulik CM, Sullivan PF. The prevalence of disordered eating behaviours and attitudes in adolescent girls. $N Z J$ Psychol 1996; 25:7-12. 